\title{
ESTIMATING TRACK CAPACITY BASED ON RAIL STRESSES AND METAL FATIGUE
}

\author{
David Y. Jeong \\ A. Benjamin Perlman \\ Volpe National Transportation Systems Center \\ Research and Innovative Technology Administration \\ US Department of Transportation \\ Cambridge, Massachusetts, USA
}

\section{ABSTRACT}

This paper describes a framework to evaluate the structural capacity of railroad track to train-induced loads. The framework is applied to estimate structural performance in terms of allowable limits for crosstie spacing. Evaluation of the load-carrying capacity of track is conducted by examining the state of stress in the rail.

Rail stresses are estimated by superimposing the contributions from different sources: (1) live-load stresses, (2) thermal stresses, and (3) residual stresses. Rail bending and thermal stresses are calculated based on assuming that the rail behaves as a beam supported by a linear elastic foundation. The classical beam on elastic foundation analysis is modified in the present work to account for crosstie spacing that exceeds the limits of the classical theory. Finite element methods are used to develop an amplification factor on the bending moment calculated from beam on elastic foundation theory, which is applied when the spacing between crossties becomes discrete and the foundation support is no longer considered as continuous.

The rail stress analysis is then used in conjunction with a failure criterion based on the formation and growth of internal defects in rail due to the repeated passage of wheels, i.e. metal fatigue. A similar methodology was applied in previous work to estimate allowable limits for rail head wear in terms of vertical head-height loss and gage-face side wear. Moreover, allowable limits estimated from this methodology are inherently linked with the frequency of rail testing to detect internal rail head defects and mitigate the likelihood of accidents from broken rails.

The analyses described in this paper depend on various assumptions regarding operational, structural and environmental factors. These factors include vehicle weight, train speed, rail size, foundation modulus, temperature differential (i.e. difference between the rail temperature and the stress-free or neutral temperature), and rail test interval (i.e. tonnage between rail tests). Sensitivity studies are conducted to examine the relative effect of these factors on the estimation of maximum free span between effective ties. In addition, results from applying the methodology described in this paper are compared to the limits specified in the current track safety regulations.

\section{INTRODUCTION}

Railroad tracks are supported by ballast, crossties, and assembly fittings to transmit and distribute wheel loads to the subgrade. The structural support restrains the track from movement in the lateral, longitudinal, and vertical directions under dynamic wheel loads and thermal stresses. Moreover, the quality of the track structure is defined by rail size and support characteristics.

In the analysis of track structures, the distinguishing parameters for rail size are the area moments of inertia and the dimensions describing the rail cross section. Support characteristics have two distinct aspects. Crossties are described by their spacing and condition, i.e. whether they provide effective support or not (e.g. missing tie). Tie size does not enter in the calculation. Stiffness of the track below tie level is prescribed by foundation moduli to resist vertical, lateral and twist displacement of the rail.

The flexural behavior of a rail in track under passing wheel loads can be accurately assessed using an analysis of the rail as a uniform beam on elastic foundation. Rail stresses, however, are also dependent on local variations in support stiffness and the ability of the structure to transfer applied loads to the supports. In addition, heavy trains operating at high speeds can initiate a cycle of accelerated degradation of geometry that feeds back through vehicle response to track irregularities to cause even larger demands on the track.

Requirements for crosstie spacing are specified in the Track Safety Standards (TSS), and are published in the Code of Federal Regulations 49 CFR §213.109 [1]. Amendments and modifications to the regulations may be achieved through the 
rulemaking process developed by the Federal Railroad Administration (FRA) which is guided by the Rail Safety Advisory Committee (RSAC). The RSAC was formed to facilitate negotiated rulemaking for the purposes of revising the FRA safety standards. Revisions to the regulations may be needed to compensate for the increasing trends of heavier axle loads and faster train speeds placed on rail transportation. Results from technical studies may provide the rational basis to revise the existing regulations.

This paper describes a framework to provide a rational basis for estimating the structural capacity of railroad track. The framework is applied to calculate the largest allowable spacing between effective crossties in track. The framework assumes that internal defects develop and grow in rail due to the repeated passage of trains, i.e. metal fatigue. Fatigue and fracture analyses are applied to calculate the growth rate of the defects and to predict the critical conditions when the defects become large enough to cause a broken rail. A similar methodology was originally developed and applied to estimate limits for rail head wear [2, 3]. These analyses and methods were developed over the course of ongoing research sponsored by the FRA Office of Research and Development and conducted by the Volpe National Transportation Systems Center (Volpe Center).

\section{FRAMEWORK FOR ESTIMATING TRACK CAPACITY}

A general framework to evaluate the structural limitations of track to train-induced loads is illustrated in Figure 1. Operational factors are shown to determine the magnitude of the applied wheel loads. These operational factors include the characteristics of different car types, such as vehicle weight and axle spacing, in combination with train speed and track condition (i.e. alignment, profile, cross-level, and gage). In principle, speed and track condition are separate factors. In practice, however, the two are related: higher maximum operating speeds for both freight and passenger traffic are allowed in the regulations as the track classification becomes higher. Improved track conditions are implied as the track classification becomes higher. Structural factors are shown to comprise the rail and the support conditions (i.e. foundation and ties). The response of the track structure to the applied wheel loads is then calculated in terms of rail stresses. To evaluate the load-bearing capacity of rail, a criterion is assumed to define a stress state beyond which represents catastrophic failure of the rail.

One criterion is to assume that the maximum rail stress cannot exceed a limiting value, such as the yield strength of the rail steel. Under train-induced loading, the maximum tensile stress occurs at the field-side corner of the rail base (see Figure 2). Assuming such a criterion presumes that yielding of the extreme fibers in the rail base results in catastrophic rail failure. Experience, however, suggests that the result of a single exceedance of yield strength in the maximum fiber of the rail base would seldom result in rail failure under passage of a train. Since rail loads are cyclic, an evaluation of rail structural integrity based on fatigue crack growth is considered as a reasonable alternative failure criterion. For this purpose, a particular defect, called a detail fracture, is assumed to be present in the upper gage corner of the rail head because it is most common transverse rail head defect found in continuous welded rail (CWR) in North America. The growth behavior of detail fractures has been studied in previous research sponsored by the FRA [4-6]. Moreover, the analyses described subsequently in this paper are based on the results from the previous research.

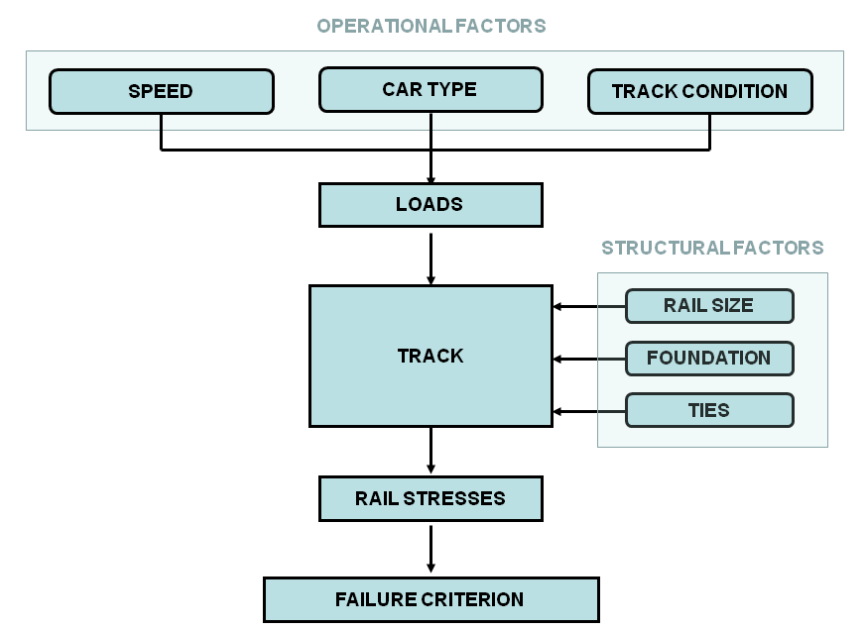

Figure 1: Flow Diagram for Estimating Track Capacity Limits

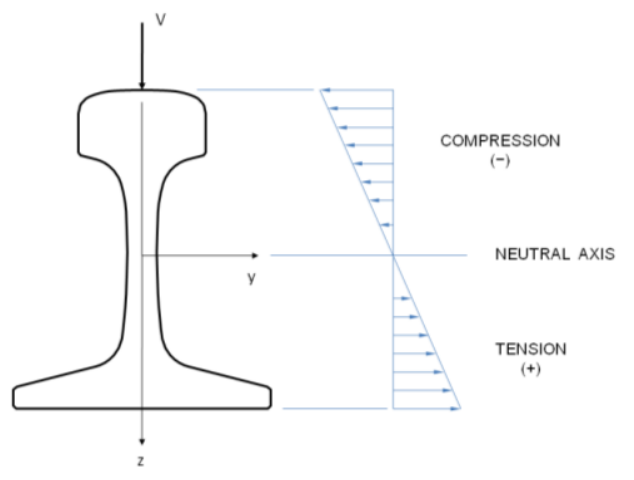

Figure 2: Rail Bending Stress due to Vertical Load

The stress distribution shown schematically in Figure 2 is based on a vertical wheel load applied directly at the vertical centerline of the rail. However, eccentricity of the path of loaded wheels from the rail centerline distorts the flexure of the rail by imposing a twisting torque on the rail. Similarly, lateral loads on the rail resulting from truck guidance and hunting produce both a twisting torque and a lateral thrust. The different deflection modes produced by these two kinds of loads are shown in Figure 3. A theory that allows for the coupled twist and flexure of the rail was developed by Timoshenko and Langer [7]. Further details of the stress analysis of rail used in the present work are described in the appendix. 

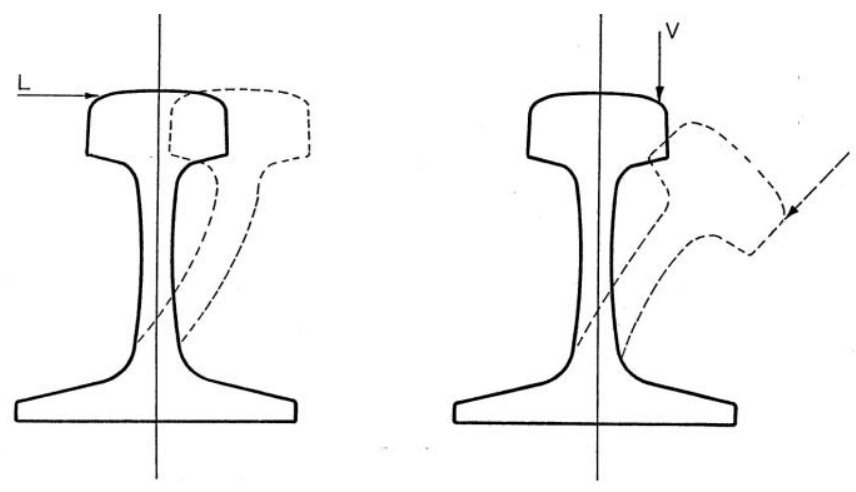

Figure 3: Rail Deflection from Lateral and Eccentric Vertical Loads

\section{Effect of Train Speed}

In order to relate rail stresses to operating conditions, information linking wheel/rail loads to dynamics of train operations is needed. In practice, the accepted approach in analyzing the behavior of wheel-rail loads with speed is based on using a dynamic load amplification factor. These factors have been developed on the basis of empirical observations.

Measurements at a given location include a large range of values because so many variable factors affect dynamic load levels. A basic characteristic of vertical loads is the static car weight. However, dynamic interaction between vehicles and track produces vertical loads that fluctuate with respect to the static value. Lateral forces are generated by the vehicle response to track geometry irregularities, components of longitudinal train-action forces, external disturbances such as wind forces, self-excited hunting motions, and creep and flange forces necessary to guide the vehicle through curves.

Dynamic loads on revenue track have been measured with instrumentation onboard individual cars running over track (referred to as "car data") as well as with wayside instrumentation surveying wheel passages at fixed track locations (referred to as "traffic data") [8-10]. The available data can be correlated with a speed factor recommended by AREMA [11]:

$D L F=1+\frac{33 v}{100 D}$

where $D L F$ is the dynamic load factor, $v$ is the train speed in miles per hour and $D$ is the wheel diameter in inches. This factor does not include the effect of variations in track geometry or vehicle type.

\section{Effect of Discretely Supported Track}

In reality, the spacing between effective crossties is finite or discrete rather than continuous. In theory, the assumption of a continuous elastic foundation to estimate rail stresses for crosstie track has been shown by Hetenyi [12] to be limited by the requirement that at least four ties should be within the wavelength of the deflection line. In terms of uniform tie spacing in discretely supported track (as shown in Figure 4), this requirement is

$$
L<\frac{\pi}{4 \lambda}
$$

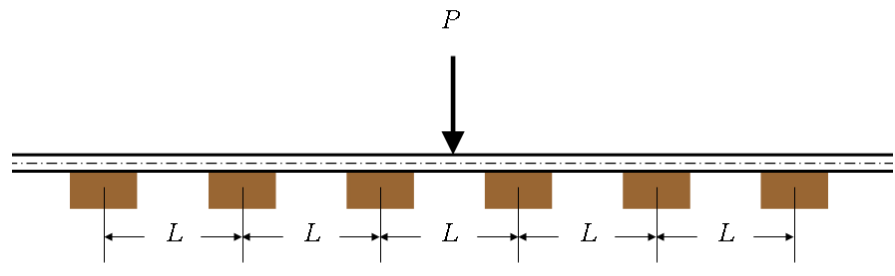

Figure 4: Uniform Tie Spacing in Discretely Supported Track

In equation (2), $L$ is the uniform spacing between ties and $\lambda$ is a characteristic wavelength that depends on the bending rigidity of the rail and the effective stiffness or modulus of the continuous foundation. From beam on elastic foundation theory,

$\lambda=\sqrt[4]{\frac{k}{4 E I}}$

where $k$ is the foundation modulus in lb per unit area, $E$ is the modulus of elasticity for rail steel, and $I$ is the bending inertia of the rail in inch ${ }^{4}$. Equivalently, equation (2) may be recast as

$\lambda L<\frac{\pi}{4}=0.785$

Figure 5 shows the limits of maximum tie spacing given by equation (2) for vertical bending of typical rail and foundation modulus combinations. As rail size increases, the maximum tie spacing increases. However, as support conditions improve and foundation modulus increases, the maximum tie spacing to maintain the continuous foundation assumption decreases. Moreover, the limits shown in this figure indicate that maximum tie spacing depends on rail size as well as foundation modulus. These results apply only to the case of pure vertical beam flexure where the state of stress is calculated at the field-side corner of the rail base.

The beam on elastic foundation theory represents idealized conditions. Therefore, a numerical study was conducted to develop a modification to the continuous foundation analysis for support conditions that deviate from idealized, and to account for crosstie spacing beyond the limit given by equation (2). The numerical study was carried out using finite element analysis of a beam representing a single rail supported by a series of discrete springs representing uniform tie spacing as shown in Figure 6. 


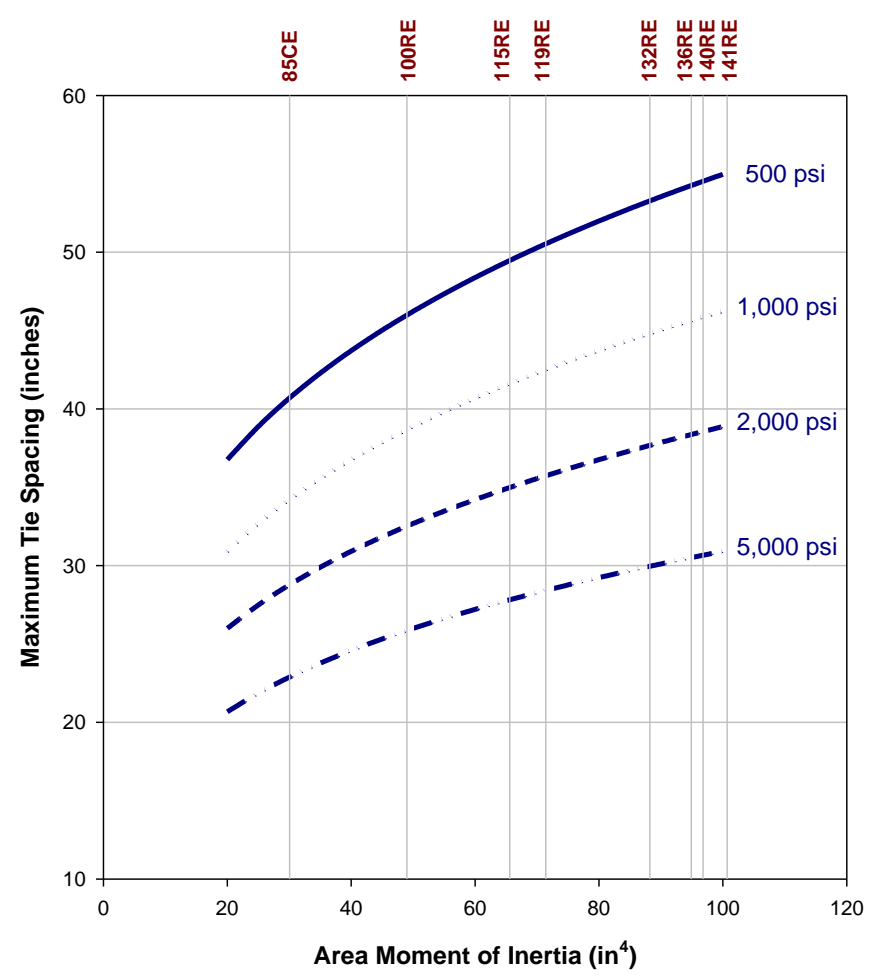

Figure 5: Maximum Tie Spacing for Combinations of Rail Size and Continuous Foundation Modulus

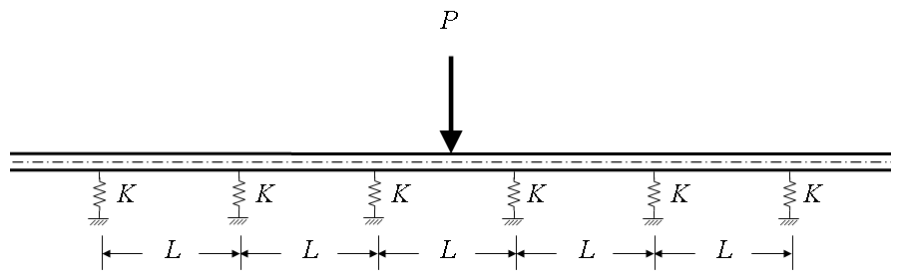

Figure 6: Rail Supported by Discrete Springs with Uniform Spacing

Finite element analysis is applied to calculate the maximum bending moment, $M_{C}$ for discretely supported track, which is then compared to the corresponding continuous foundation solution. The maximum bending moment from beam on elastic foundation theory is

$M_{0}=\frac{P}{4 \lambda}$

The concentrated load in the finite element analyses is applied mid-span or between springs representing crossties, as shown in Figure 6. In the case of discretely supported track, the spring constant shown in Figure 6 is related to the foundation modulus by

$K=k L$
The numerical study was carried out for several cases that include: (1) varying rail size (85 ASCE and $132 \mathrm{RE}$ ), (2) varying foundation modulus (1000 psi and $5000 \mathrm{psi}$ ), (3) varying tie spacing while holding spring stiffness constant. Results from the finite element analyses for all of these cases are plotted in terms of moment ratio, $M_{C} M_{0}$ as a function of $\lambda L$ in Figure 7. The physical interpretation of increasing $\lambda L$ is that track condition is deteriorating from the idealization of a continuous foundation. The figure indicates that the moment ratio increases monotonically as the tie spacing deviates from the condition prescribed by equation (2). Figure 7 also shows results from a regression analysis of the finite element results. The following equation provides an excellent curve fit with the maximum moment ratio for discretely supported rail:

$\frac{M_{C}}{M_{0}}=1-0.078 \lambda L+0.197 \lambda L^{2}-0.018 \lambda L^{3}$

Moreover, this equation is used in subsequent calculations to amplify the bending moment for vertical bending for values of $\lambda L$ that exceed the limit given by equation (4).

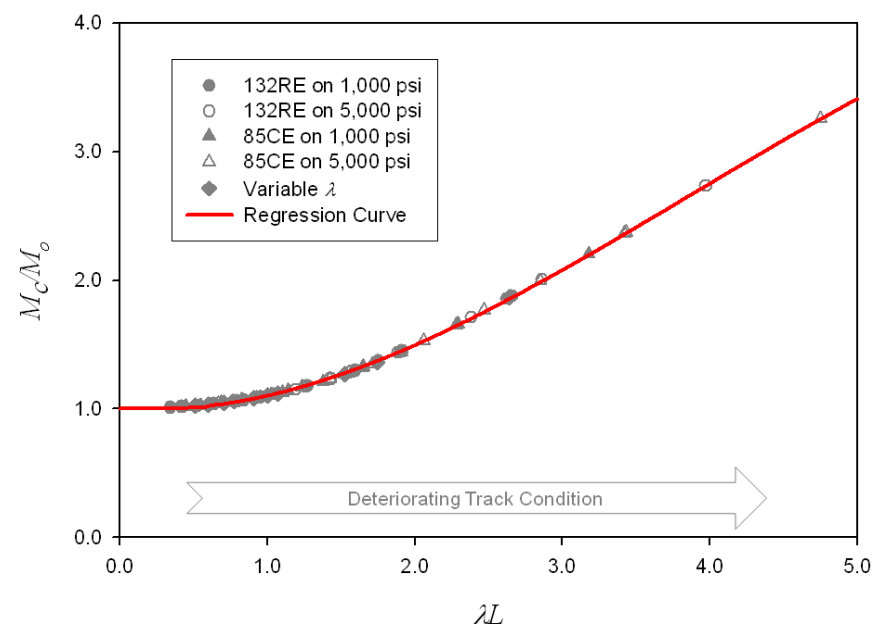

Figure 7: Moment Ratio as a Function of $\lambda L$

A similar numerical study was carried out using finite element analysis to examine the load transfer behavior for laterally applied loads, as shown in Figure 8. A lateral load applied to only one rail is shared through the ladder-type construction of the track, as shown schematically in Figure 9. The load-sharing capability of the track is manifested through the axial stiffness of the crossties represented by the spring model shown in Figure 10. In this figure, $K_{L}$ represents the stiffness offered by the lateral foundation and $K_{G}$ is the gage stiffness. The lateral foundation is assumed to be proportional to the vertical foundation and the gage stiffness determines the amount of spreading between rails. 


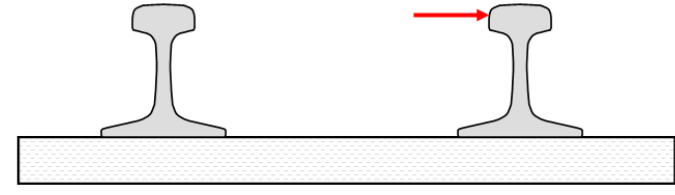

Figure 8: Lateral Load Applied to Single Rail

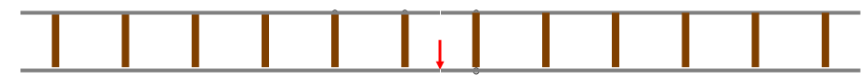

Figure 9: Lateral Load Applied to Single Rail in Ladder-like Track

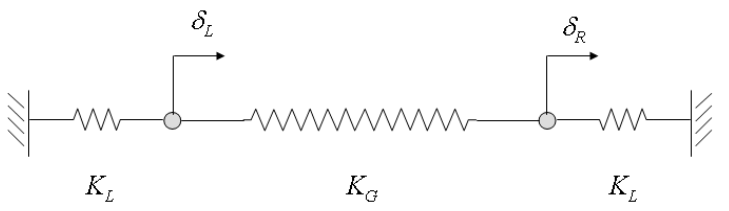

Figure 10: Spring Representation of Laterally Loaded Track

In the finite element analysis, the ties and rails are connected at nodes in a manner equivalent to a model of a frame structure. With this restriction noted, the lateral load transfer characteristics were examined for 85 ASCE and $132 \mathrm{RE}$ rail with poor and good foundation support with a variation in uniform tie spacing as in the previous case for vertically applied loads. Additional results were calculated for $100 \mathrm{RE}, 115 \mathrm{RE}$, $136 \mathrm{RE}$ and $140 \mathrm{RE}$ rail. The value of the gage stiffness is varied over three orders of magnitude $\left(10^{4}\right.$ to $10^{6} \mathrm{lb}$ per inch).

The finite element results for the lateral load cases are shown in Figure 11 for a gage stiffness of $10^{6} \mathrm{lb}$ per inch. Similarly, FE results for lateral loads are shown in Figure 12 for $K_{G}=10^{5} \mathrm{lb}$ per inch and in Figure 13 for $K_{G}=10^{4} \mathrm{lb}$ per inch. In these results, the characteristic wavelength $\lambda$ is based on the lateral bending inertia of the rail and on the lateral foundation modulus. As in the vertical load case, the moment ratio for laterally applied loads increases monotonically as $\lambda L$ increases. For values of $\lambda L$ exceeding the limit in equation (4), the dependence of the moment ratio on the gage stiffness diminishes. These results also indicate that as the gage stiffness is reduced, the moment ratios at small values of $\lambda L$ approach unity. In the limiting case of no gage stiffness, the moment ratio curve for lateral loads is equal to the moment ratio curve for vertical loads.

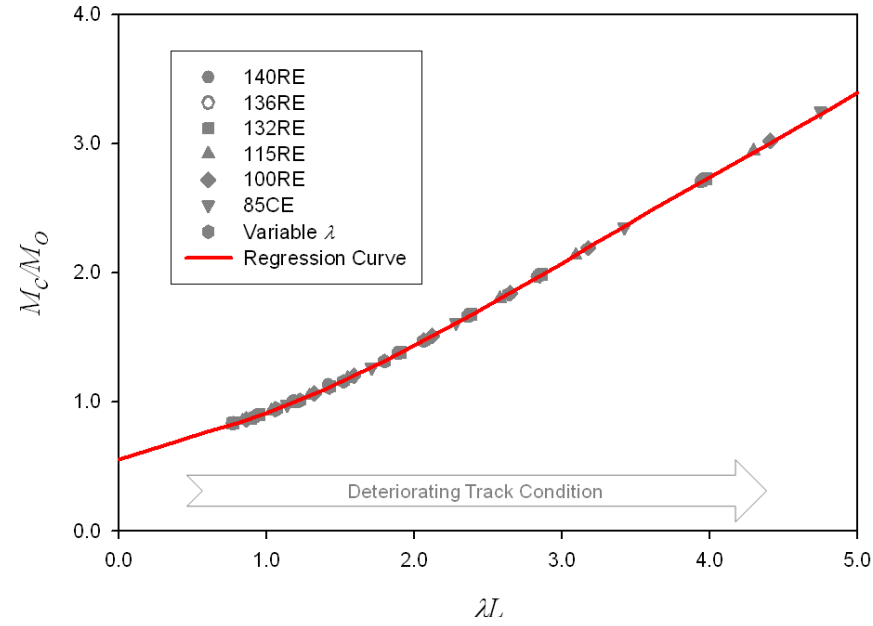

Figure 11: Moment Ratio for Laterally Loaded Track $\left(K_{G}=10^{6} \mathrm{lb} / \mathrm{in}\right)$

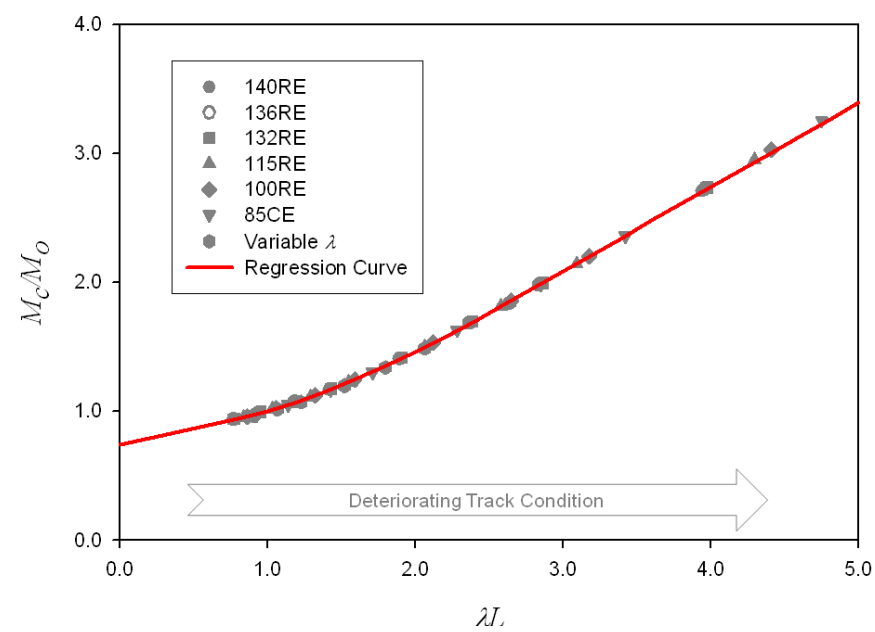

Figure 12: Moment Ratio for Laterally Loaded Track $\left(K_{G}=10^{5} \mathrm{lb} / \mathrm{in}\right)$

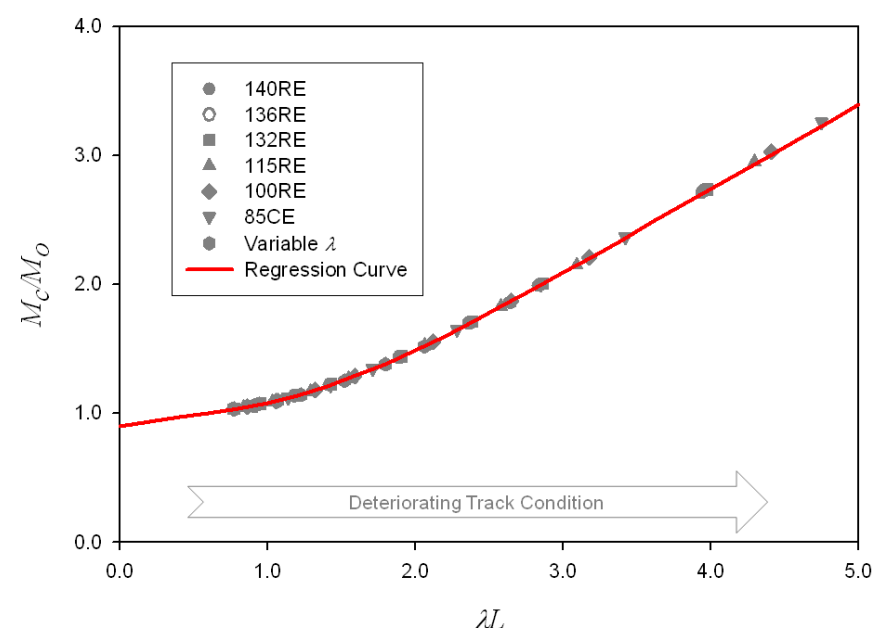

Figure 13: Moment Ratio for Laterally Loaded Track $\left(K_{G}=10^{4} \mathrm{lb} / \mathrm{in}\right)$ 


\section{CROSSTIE SPACING BASED ON METAL FATIGUE}

The failure criterion assumed in the framework for estimating track capacity in terms of maximum allowable tie spacing is fatigue crack growth. The application of engineering fracture mechanics or damage tolerance principles to examine the propagation or growth of detail fractures in the rail head is described in [4-5].

In the present work, the stress analysis in the fatigue crack growth calculations is modified to account for the effect of discretely supported track. For continuously supported rails, the maximum rail stress is independent of the location of the applied load relative to a tie. As the track condition deteriorates, with loss of support at some tie locations, more of the load is carried by the rail bending strength over the span between effective ties. Under these circumstances, the maximum stress can be greatly magnified compared with its uniform support value. Therefore, the rate at which defects propagate or grow is expected to accelerate as the maximum rail stresses increase.

Figure 14 shows a schematic of the growth curves for three detail fractures which only differ by the uniform tie spacing. Detail fractures are assumed to grow faster as the spacing between effective ties increases because of a corresponding increase in the bending moment, which in turn raises the rail stresses. Each of the growth curves assumes a constant and moderate temperature differential. That is, the rail temperature is below the stress-free or neutral temperature, which creates longitudinal tensile thermal stresses in the rail. The starting point of each growth curve represents the initial defect size or the size at which an internal defect becomes barely detectable. The endpoint of each curve in this schematic represents the point when the life of the rail containing the defect has been exhausted.

Rail failure, however, may occur at any point along the growth curve due to an extreme event such as a high impact load from a flat or out-of-round wheel in cold weather. Figure 15 shows a family of growth curves in which the endpoints represent the defect size (and tonnage) at which rail failure is expected to occur during a sudden drop in temperature (i.e. extreme temperature differential). The tonnage to grow the defect from the initial, barely detectable size to the critical size is referred to as the slow crack-growth life. Moreover, the slow crack-growth life represents the window of opportunity to find the defect before rail failure may occur.

Therefore, an appropriate rail test interval is one that is less than or equal to the slow crack-growth life. Figure 16 shows that the maximum allowable span between effective ties corresponds to the growth curve in which the tonnage to grow a defect to the critical size is equal to the rail test interval.

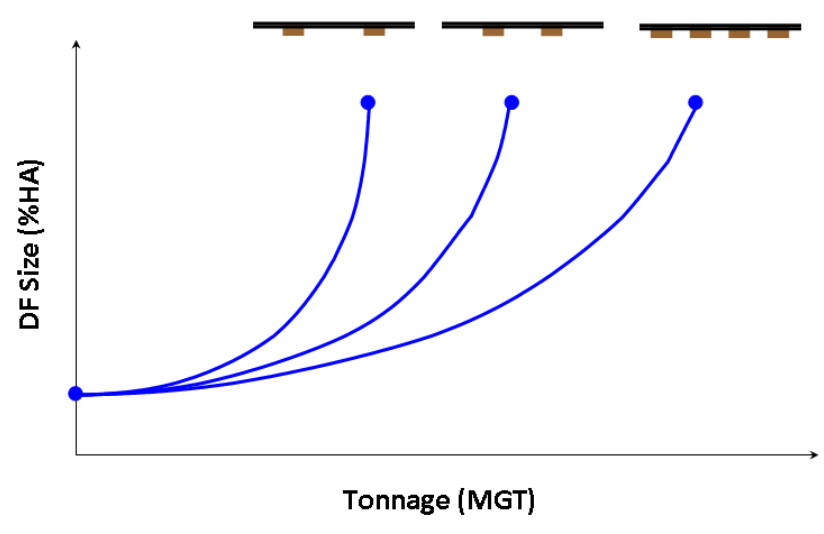

Figure 14: Effect of Tie Spacing on Defect Growth Rate

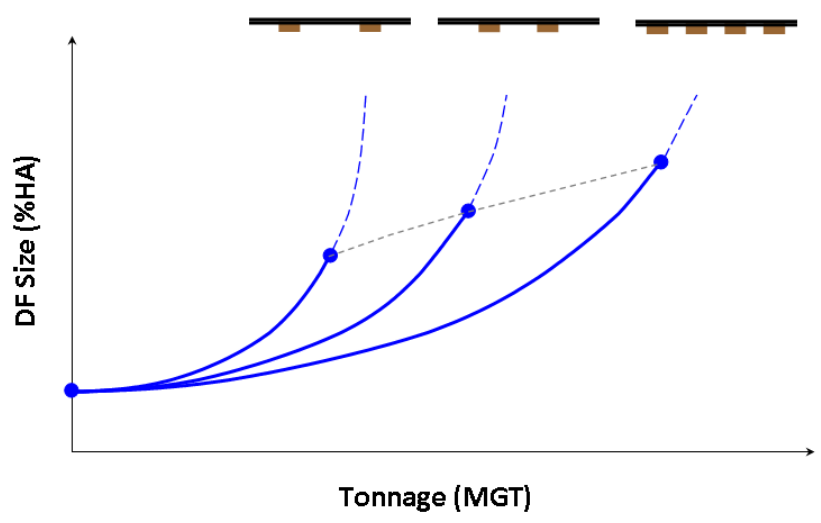

Figure 15: Critical Defect Size

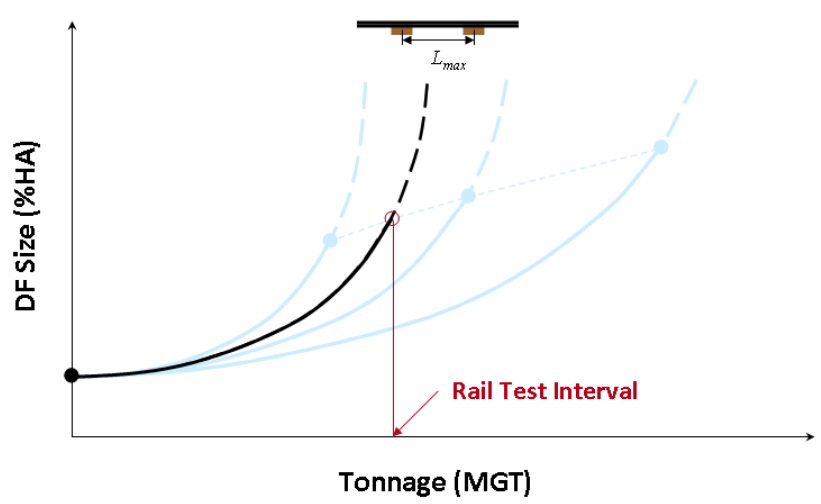

Figure 16: Free Span Estimation Based on Rail Test Interval 


\section{RESULTS}

A sensitivity study is conducted to examine the relative effect of the various factors on the maximum free span between effective ties. Baseline values are assumed for each factor, and then varied one factor at a time while holding the other factors equal to their respective baseline values. Table 1 lists the different factors considered in the present study, the assumed baseline values, and the range of values that are varied from the baseline for each factor. The baseline values are intended to represent typical operational, structural, and environment conditions. The moderate temperature differential is used to calculate defect growth while the extreme temperature difference is used to determine the critical defect size (i.e. defect size at which rail failure is expected to occur).

Table 1: Factors and Assumed Values

\begin{tabular}{lcc}
\hline Factor & $\begin{array}{c}\text { Baseline } \\
\text { Value }\end{array}$ & Range of Values \\
\hline Maximum Static Wheel Load & $34.75 \mathrm{kips}$ & 29.75 to 39.75 \\
Average Static Wheel Load & $16.5 \mathrm{kips}$ & 10 to 33 \\
Train Speed & $40 \mathrm{mph}$ & 10 to 80 \\
Rail Test Interval & $20 \mathrm{MGT}$ & 10 to 30 \\
Rail Size & $115 \mathrm{RE}$ & 100RE to $141 \mathrm{RE}$ \\
Track Curvature & Tangent & Tangent to $5^{\circ}$ curve \\
Fracture Toughness & $35 \mathrm{ksi-in^{1/2 }}$ & 25 to 45 \\
Vertical Modulus & $2,000 \mathrm{psi}^{\circ}$ & 1,000 to 5,000 \\
Moderate $\Delta \mathrm{T}$ & $15^{\circ} \mathrm{F}$ & 5 to 25 \\
Extreme $\Delta \mathrm{T}$ & $50^{\circ} \mathrm{F}$ & 30 to 70 \\
\hline
\end{tabular}

Figure 17 shows the relative effect of the different factors on the maximum allowable free span between effective ties. Assuming the baseline values for each factor, the allowable tie spacing is estimated to be 102.4 inches. The figure displays the variation in allowable tie spacing as the baseline values are altered. The factors are listed by the order in which the altered value produces the largest free span. For example, the span between ties increases from the baseline of 102.4 inches to 138.7 inches when the rail test interval is reduced from 20 MGT to $10 \mathrm{MGT}$. Increasing the frequency of rail tests, reducing the average static wheel load, and increasing rail section will increase the allowable spacing between ties. Conversely, heavier static wheel loads, faster train speeds, weaker material in terms of fracture toughness, and curved track require smaller spacing between ties. In the present calculations, the effect of track curvature is carried out by applying higher lateral wheel loads. For $5^{\circ}$ curve, a lateral-to-vertical load ratio of 0.4 is assumed.

The length of the bars in the figure represents the range of allowable tie spacing corresponding to the range of the value for each factor. For example, varying the static wheel load from 33 kips to 10 kips corresponds to a range of allowable tie spacing between 45.4 and 121.8 inches. Moreover, the results indicate that average static wheel load, rail test interval, and train speed have the most significant effect on the allowable spacing between crossties. Conversely, the maximum static load and extreme temperature differential have the weakest effect.

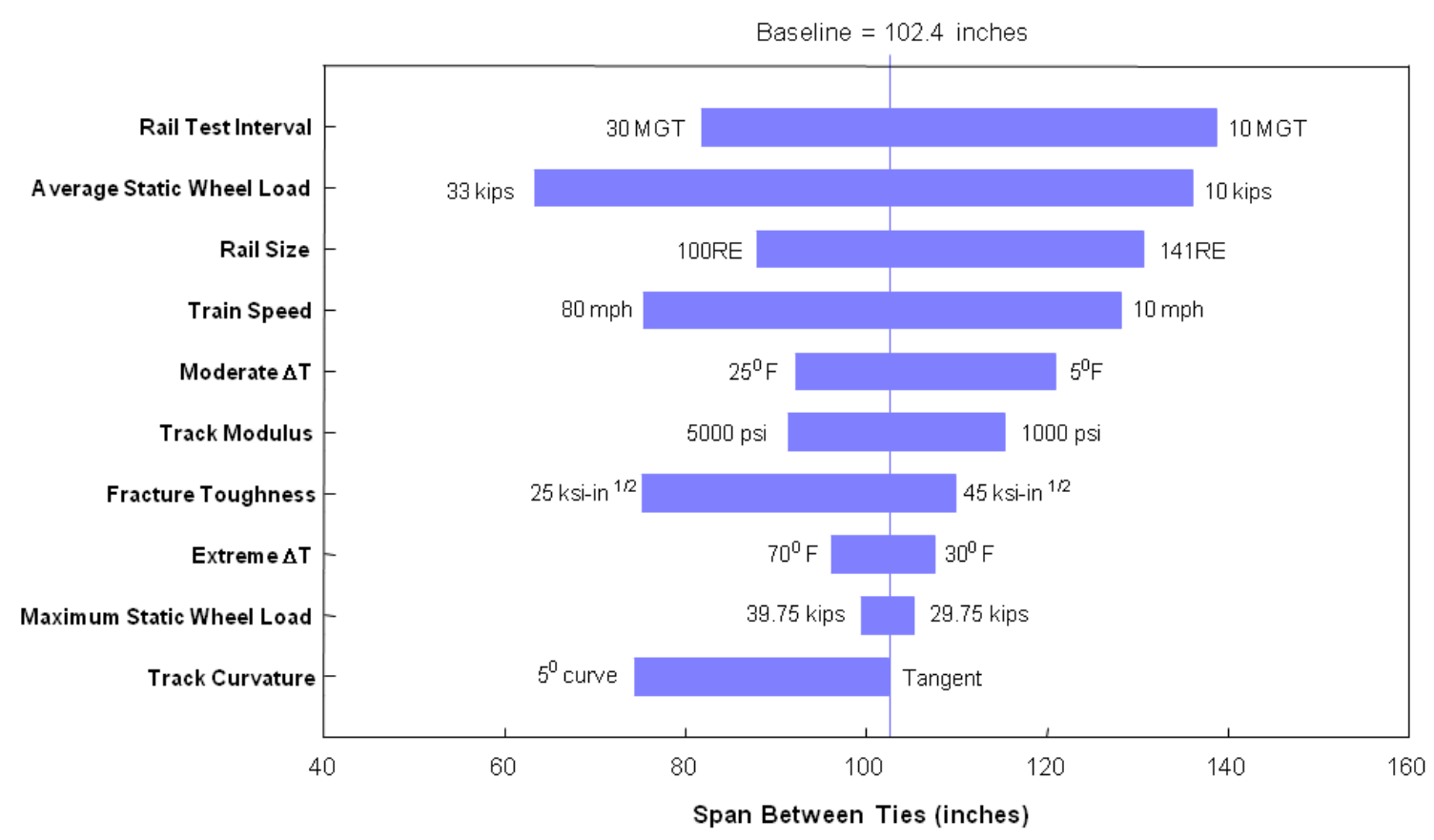

Figure 17: Relative Effect of Different Factors on Span between Crossties 
CFR §213.9 lists the maximum allowable operating speed for freight trains travelling over different classes of track. The maximum train speed as specified in the CFR and the vertical support conditions assumed in the present calculations for each track class are summarized in Table 2. Lateral foundation modulus is assumed to be 85 percent of the assumed vertical modulus in all calculations.

Table 2: Summary of Track Characteristics

\begin{tabular}{ccc}
\hline $\begin{array}{c}\text { FRA } \\
\text { Track }\end{array}$ & $\begin{array}{c}\text { Max. Train } \\
\text { Speed } \\
\text { Class }\end{array}$ & $\begin{array}{c}\text { Vertical } \\
\text { Modulus } \\
\text { (mpi) }\end{array}$ \\
\hline 1 & 10 & 1,000 \\
2 & 25 & 1,000 \\
3 & 40 & 2,000 \\
4 & 60 & 2,000 \\
5 & 80 & 5,000 \\
\hline
\end{tabular}

CFR §213.109 specifies the minimum number of crossties within each 39-foot segment by different classes of track. Figure 18 compares the allowable spans between ties estimated by the current approach to the CFR requirements for tangent track. Results from the current approach are based on assuming the baseline values for each factor, except for train speed and vertical modulus which are specified in Table 2 and rail size which is indicated in the figure. The CFR specifies that each 39-foot segment of Class 1 track shall have five crossties. The scale on the right-hand side of the figure is such that the whole number on the axis times the corresponding value on the lefthand side is equal to 468 inches or 39 feet. Therefore, the span between ties based on the CFR for Class 1 track is 93.6 inches. Moreover, the span between ties estimated by the current approach is greater than the CFR requirement for each of the three rail sizes in each of the five track classes shown in the figure.

Figure 19 shows the corresponding comparison between the CFR requirements and the estimated spans for curved track. In the case of curved track, a lateral-to-vertical wheel load ratio of 0.4 is assumed. Increased lateral bending amplifies rail stresses, which places greater a demand on the structural capacity of the track. To compensate for the increased demand on structural capacity, the span between crossties is less in curved track than in tangent, which is consistent with the CFR requirements. The span between ties as estimated by the current approach is greater or equal to that for the CFR for the three different rail sizes for Classes 1 through 4 . In Class 5 track, however, the estimated span for 100RE and $115 \mathrm{RE}$ rails are less than those required by the regulations.

CFR \$213.109 specifies not only the minimum number of crossties within a 39-foot segment but also requirements that each of the crossties must satisfy. These requirements are intended to define tie conditions that provide effective support to the track. In reality, the crossties have varying degrees of effectiveness. Therefore, the number of effective crossties specified in the CFR need to be conservative. This conservatism is borne out in the results from applying the current methodology.

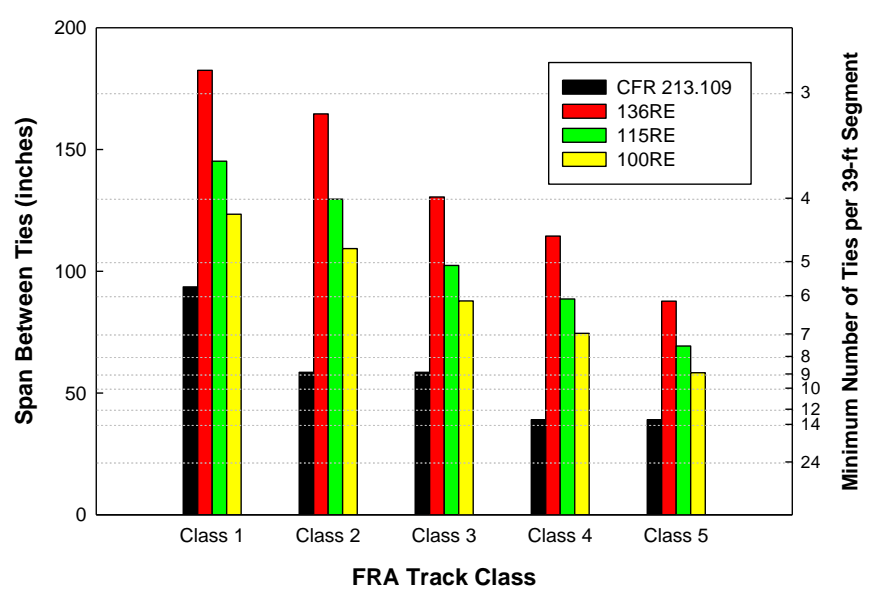

Figure 18: Comparisons with CFR § 213.109 for Tangent Track

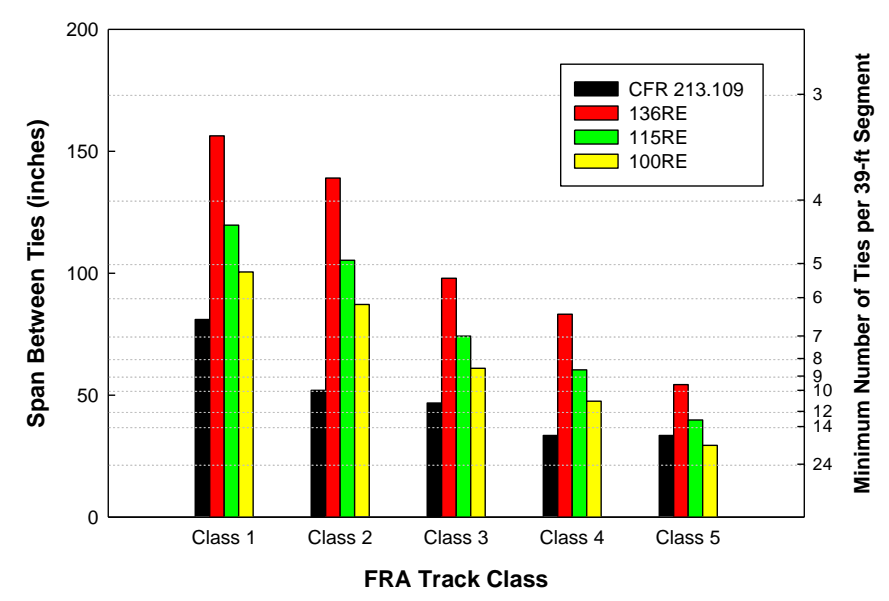

Figure 19: Comparisons with CFR § 213.109 for Curved Track

\section{DISCUSSION}

The general framework presented in this paper depends on various assumptions regarding operational, structural, and environmental factors. Among the operational factors is track condition. While in theory, train speed and track condition are separate factors, they are linked in the current framework through FRA Track Class. However, factors characterizing track condition in terms of track geometry such as alignment, cross-level, and gage have not been explicitly taken into account in the present analysis. Moreover, requirements for track geometry are prescribed in Subpart C of the Track Safety Standards, which have been harmonized with the requirements in Subpart D for ballast and crossties.

Calculations are presented in this paper only for FRA Track Classes 1 through 5. Both freight and passenger traffic are carried on these classes of track. Train operations at speeds 
greater than $90 \mathrm{mph}$ for passenger equipment and greater than $80 \mathrm{mph}$ for freight equipment are considered as high-speed operations. Moreover, the safety requirements for high-speed track classes are covered in Subpart G of the Track Safety Standards.

Current regulations for crosstie spacing are independent of rail size. The limits specified in current regulations for crosstie spacing on tangent track are more conservative than those estimated by the current approach. However, the limits specified in current regulations for light rail on high track classes on curves are less conservative than those estimated by the current approach.

By assuming a failure criterion associated with the initiation and growth of internal rail defects that may lead to rail failure, the current approach relates the spacing between effective crossties to the risk of rail failure. Moreover, the current approach provides a rational basis to estimate variations from the track safety standards by defining the frequency of rail testing to mitigate this risk. That is, results from the sensitivity study indicate that rail test interval has a significant effect on the estimated span between crossties. Longer spacing between ties could be acceptable if more frequent rail testing is conducted. Conversely, shorter spacing between ties could be used with less frequent testing.

The calculations presented in this paper apply to conventional train operations in which wooden crossties are generally used in construction of track. In high speed track classes, concrete ties are an alternative, which may also offer advantages over wooden ties. Research is ongoing to examine the structural performance of concrete ties. The results of the concrete tie research will be communicated in future publications.

\section{CONCLUDING REMARKS}

This paper describes a general framework to evaluate the structural limits of track to train-induced loads. Structural capacity of track is evaluated in terms of rail stresses. Rail stresses are calculated using a theory that allows for the coupled twist and flexure of the rail. The framework requires an assumption regarding failure criterion. In the present work, the framework uses a failure criterion based on fatigue crack growth of internal rail head defects to estimate limits for maximum span between effective crossties. Thus, allowable limits estimated from this methodology are inherently linked to the frequency of rail testing to detect internal rail head defects and mitigate the likelihood of accidents from broken rails.

Results are presented in which FRA track class is characterized by a combination of maximum train speed for freight traffic and track condition, which is defined in terms of foundation modulus. Sensitivity studies indicate that static load, rail test interval (or frequency of rail testing), train speed, and rail size have the greatest effect on the maximum span between effective ties.

\section{ACKNOWLEDGMENTS}

The work described in this paper was carried out under the Rail Integrity Project in the Track Safety Research Program sponsored by the Office of Research and Development, Federal Railroad Administration, US Department of Transportation, under the direction of Mr. Gary Carr, Chief of the Track Research Division. Mr. Ali Tajaddini is the Project Manager for the research related to rail integrity.

\section{REFERENCES}

[1] Code of Federal Regulations, Title 49 - Transportation, Part 213 - Track Safety Standards, Section 213.109 Crossties, Federal Railroad Administration, October 2009.

[2] Jeong, DY, Tang, YH, Orringer, O. "Estimation of Rail Wear Limits Based on Rail Strength Investigations," Volpe Center Final Report DOT/FRA/ORD-98/07, December 1998.

[3] Lyons, ML, Jeong, DY, Gordon, JE. "Fracture Mechanics Approach to Estimate Rail Wear Limits," Proceedings of the 2009 ASME Rail Transportation Division Fall Technical Conference, RTDF2009-18035, October 2009.

[4] Orringer, O, Tang, YH, Gordon, JE, Jeong, DY, Morris, JM, Perlman, AB. "Crack Propagation Life of Detail Fractures in Rails," Volpe Center Final Report DOT/FRA/ORD-88/13, October 1988.

[5] Jeong, DY, Tang, YH, Orringer, O. "Damage tolerance analysis of detail fractures in rail," Theoretical and Applied Fracture Mechanics 28 (1997) 109-115.

[6] Clayton, P, Tang, YH, "Detail fracture growth in curved track at the Facility for Accelerated Service Testing," Residual Stresses in Rails, Vol. 1, Kluwer Academic Publishers, The Netherlands (1992) 37-56.

[7] Timoshenko, S, Langer, BF. "Stresses in Railroad Track," ASME Transactions 54 (1932) 277-293.

[8] Ahlbeck, DR, Johnson, MR, Harrison, HD, Tuten, JM. "Measurements of Wheel/Rail Loads on Class 5 Track," Final Report, DOT/FRA/ORD-80/19, 1980.

[9] Johnson, MR, "Summarization and Comparison of Freight Car Truck Load Data," ASME Transactions, Journal of Engineering for Industry 100 (1978) 60-66.

[10] Tuten, JM, Harrison, HD. "Design, Validation, and Application of a Monitoring Device for Measuring Dynamic Wheel/Rail Loads," Proceedings of the ASME Winter Annual Meeting, Paper No. 84-WA/RT-10 (1984).

[11] AREMA Manual for Railway Engineering, Vol.1: Track, American Railway Engineering and Maintenance-of-Way Association, 1-2-21 (1999).

[12] Hetenyi, H. Beams on Elastic Foundation, University of Michigan Press, Ann Arbor, MI (1974).

[13] Orringer, O. "How residual stresses can affect rail performance," Rail Quality and Maintenance for Modern Railway Operation, edited by J.J. Kalker, et al., 253-271, 1993. 


\section{APPENDIX - STRESS ANALYSIS}

Rail stresses that drive the formation and growth of detail fractures is a superposition of stresses from different sources such as applied loads, thermal expansion or contraction, and manufacturing. These stresses may be categorizes as: (1) liveload stresses, (2) thermal stresses, and (3) residual stresses. Figure 20 shows a schematic of the distributions for each of these stresses through the rail cross section.

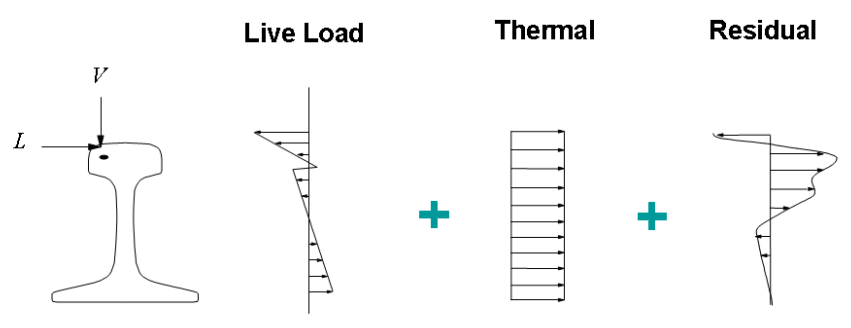

Figure 20: Superposition of Stresses

\section{Live Load Stresses}

The relationship between the loads produced by train operations at various speeds and the response of the track establishes the rational basis to evaluate the structural limitations of track. The flexural behavior of rail in track under passing wheel loads can be accurately assessed using an analysis of the rail as a uniform beam on a continuous elastic foundation [11]. The traditional theory of beams on elastic foundation considers the beam flexure of the rail in the vertical plane only.

The point of contact between loaded wheels and the rail head tends to vary toward the gage side of the rail centerline, approximately midway to the gage corner of the rail head. The variation of the point of contact can produce eccentric application of vertical and lateral loads. The eccentricity of load path distorts the flexure of the rail by imposing a twisting torque on the rail. Under this torque, twisting of the rail occurs, resulting in stresses within the body of the rail to resist further twist. These stresses include those that arise from out-of-plane warping of the rail cross section in addition to shear stresses normally associated with torsion of structural elements. Similarly lateral loads on the rail produce both a twisting torque and a lateral thrust. This torque also induces warping stresses from twist that alter the distribution of stresses in the rail developed by vertical flexure.

A theory that allows for the coupled twist and flexure of the rail was developed by Timoshenko and Langer [7]. Studies from applying this theory indicate that lateral forces can produce rail stresses comparable to those generated by vertical loads. Moreover, this theory is used in the present work to calculate rail stresses due to applied loads. Rail stresses are calculated assuming that the rail behaves as a beam supported by elastic foundations in the vertical, lateral, and rotational planes to resist bending and twisting in the respective directions. The live load stresses calculated from this theory comprise the following components:

(1) Vertical bending

(2) Lateral bending

(3) Constrained warping

(4) Vertical head on web bending

(5) Lateral head on web bending.

The calculation of these stress components to estimate the growth of detail fractures in the rail head is described in detail in Reference [4].

\section{Thermal Stresses}

Thermal stresses for fully constrained CWR in tangent track are be calculated from

$\sigma_{T}=E \alpha \Delta T$

where $\alpha$ is the coefficient of linear expansion $\left(6.5 \times 10^{-6}\right.$ per degree Fahrenheit), $E$ is the elastic modulus of rail steel (typically $30 \times 10^{6} \mathrm{psi}$ ), and $\Delta T$ is the temperature difference between the in-service temperature and the neutral or stress-free temperature. In the present calculations, $\Delta T$ is an assumed variable.

\section{Residual Stresses}

Residual stresses are known to be a significant component of the total stress which affects the rate of fatigue crack growth and the critical crack size at fracture, as well as rail fatigue life. Residual stresses are those that remain in an externally unloaded rail. Residual stresses may develop from: (a) heat treatment during manufacturing, (b) roller straightening, and (c) cold working from in-service loads. In this last case, the repetition of wheel passages over rail creates cyclic plastic flow from wheel/rail contact which induces residual stresses. The distribution of residual stresses is believed to stabilize to a quasi-steady state so-called shakedown state at an early stage of rail life. It has been estimated that between 10 and 100 million gross tons (MGT) of traffic are required to fully develop residual stresses in rail [13]. Moreover, the quantification of residual stresses by either experimental or analytical means has been found to be a formidable task.

In the present analysis, residual stresses are assumed to reduce as the size of the internal defect becomes larger. The physical interpretation of this assumption is that residual stresses are relieved as the defect enlarges. 